\title{
Effect of typhoons on the Korean national emergency medical service system
}

\author{
Soo Hyun Park', Won Chul Cha', Giwoon Kim², Tae Rim Lee', \\ Sung Yeon Hwang ${ }^{1}$, Tae Gun Shin', Min Seob Sim ${ }^{1}$, Ik Joon Jo ${ }^{1}$ \\ 'Department of Emergency Medicine, Samsung Medical Center, Seoul, Korea \\ ${ }^{2}$ Department of Emergency Medicine, Soonchunhyang University Bucheon Hospital, Bucheon, Korea
}

Objective While the effect of typhoons on emergency medicine has been evaluated, data are scarce on their effects on the emergency medical service (EMS). This study evaluated the effect of typhoons on EMS patients and performance.

Methods The study period was January 2010 to December 2012. Meteorological data regarding typhoons were provided by the Korean Meteorological Administration. EMS data were retrieved from the EMS database of the national emergency management agency. The database includes ambulance run sheets, which contain clinical and operational data. In this case-crossover study, the cases and controls were EMS calls on the day of typhoon warnings and calls one week prior to the typhoon warnings, respectively.

Results During the study period, 11 typhoons affected Korea. A total of 14,521 cases were selected for analysis. Overall, there were no obvious differences between the case and control groups. However, there were statistically significant differences in age, place, and time requests. There were fewer patients between 0 and 15 years of age $(P=0.01)$ and more unconscious patients $(P=0.01)$ in the case group. The EMS operational performance, as measured by the times elapsed between call to start, call to field, and call to hospital did not differ significantly. There was also no significant difference in the time from hospital arrival between the cases (28.67, standard deviation 16.37) and controls (28.97, standard deviation 28.91) $(P=0.39)$.

Conclusion Typhoons did not significantly affect the EMS system in this study. Further study is necessary to understand the reasons for this finding.

Keywords Cyclonic storms; Disasters; Emergency medical services

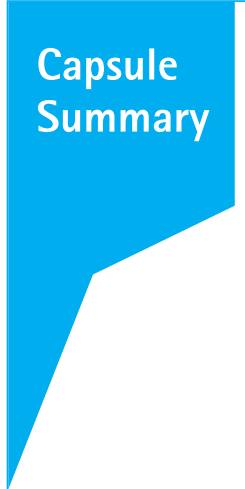

eISSN: 2383-4625

Received: July 142017

Revised: September 222017

Accepted: October 122017

Correspondence to: Won Chul Cha Department of Emergency Medicine, Samsung Medical Center, 81 Irwon-ro, Gangnam-gu, Seoul 06351, Korea E-mail: docchaster@gmail.com ORCID https://orcid.org/0000-0002-2778-2992

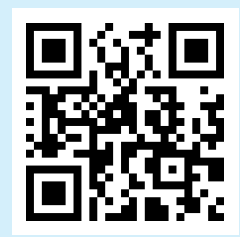

How to cite this article:

Park SH, Cha WC, Kim G, Lee TR, Hwang SY, Shin TG, Sim MS, Jo IJ. Effect of typhoons on the Korean national emergency medical service system. Clin Exp Emerg Med 2018;5(4):272-277.

This is an Open Access article distributed under the terms of the Creative Commons Attribution Non-Commercial License (http:// creativecommons.org/licenses/by-nc/4.0/). 


\section{INTRODUCTION}

Typhoons occur frequently in East Asia and the Pacific region. Several studies have reported that the typhoon intensity may increase with global warming. ${ }^{1}$ The number of severe typhoons has increased in recent decades. ${ }^{2}$ Typhoons affect tropical and subtropical zones and are often accompanied by high tides and heavy rain. ${ }^{3}$ In Korea, typhoon warnings (Kyungbo) are issued when heavy widespread damage is expected due to the weather.

The effect of typhoons on emergency medicine has been evaluated previously. Most previous research has assessed the impact of typhoons on the emergency room services, focusing on the number or patient characteristics. ${ }^{2,4}$ However, the most critical adverse effect of disasters is not only the increased medical demand but also the compromise of the healthcare system itself. The emergency medical service (EMS) is the key factor of the emergency healthcare delivery system; thus, it is important to determine the effect of natural disasters on the EMS in order to evaluate its effect on the healthcare system.

The EMS response interval is considered one of the most important emergency medical quality measures. Transportation time is one of the most important factors in emergency medical care. Ways to reduce EMS performance time have been studied in order to identify efficient solutions. ${ }^{5}$ The purpose of the present study was to evaluate the influence of typhoons on the EMS, including the patients and EMS performance.

\section{METHODS}

\section{Study setting}

The Institutional Review Board at Samsung Medical Center approved this project (2015-03-028). This study was conducted from January 2010 to December 2012 with support from the National Emergency Management Agency. The Korean EMS system is a single-tier ambulance system. All patient records are input by
EMS providers from the EMS run sheets immediately after transport. The collected data include age, sex, response time between the initial call and the ambulance arrival to the scene as well as the scene time interval from arrival to departure to the emergency department. ${ }^{6}$ EMS data for the study period were retrieved from the national EMS database. The database is composed of ambulance run sheets, which contain clinical and operational data.

\section{Meteorological data}

Meteorological data regarding typhoons were provided by the Korean Meteorological Administration (KMA). The KMA is a governmental organization under the Ministry of Environment. Its role is the observation and forecast of natural disasters and the issue of warnings regarding hazardous weather conditions. There are 97 weather stations including 10 radar installations, four upper-air obsenvation stations, and Automatic Weather Stations in Korea. ${ }^{8}$ Data were gathered from each weather station in specific regions.

The criteria used by the KMA typhoon warning system are shown in Table 1. The international classification of typhoons is described in Table 2. Any of the following are expected during a typhoon: strong wind or waves (with criteria for wind speeds for flat land and mountainous areas), total precipitation greater than $200 \mathrm{~mm}$, and storm surge expected to reach warning levels. We analyzed the intensity and pathway of typhoons, respectively, based on the KMA criteria (Table 3). Warnings were categorized into si, do units (Fig. 1).

\section{Selection of study participants}

EMS calls on the day (24 hours) of typhoon warnings were considered cases, while calls placed one week prior to typhoons (24 hours) were selected as controls (a case-crossover design). Because of differences among days of the week, the day of the previous week was chosen for the control calls. Patients transported

Table 1. Typhoon warning system of the Korea Meteorological Administration

\begin{tabular}{|c|c|}
\hline Category & Alert \\
\hline Strong wind alert & $\begin{array}{l}\text { Sustained winds speeds exceeding } 21 \mathrm{~m} / \mathrm{sec} \text { or wind gusts exceeding } 26 \mathrm{~m} / \mathrm{sec} \text { are expected on land. However, sustained wind speeds ex- } \\
\text { ceeding } 24 \mathrm{~m} / \mathrm{sec} \text { or wind gusts exceeding } 30 \mathrm{~m} / \mathrm{sec} \text { are expected in mountain areas. }\end{array}$ \\
\hline Wind wave alert & Wind speeds of $21 \mathrm{~m} / \mathrm{sec}$ or more sustained for over 3 hours at sea or significant wave heights expected to be over $5 \mathrm{~m}$. \\
\hline Storm surge & $\begin{array}{l}\text { Sea level expected to rise locally due to complex factors such as astronomical tides, storms, and low pressure and to surpass the standard } \\
\text { point to issue the advisory. } \\
\text { The standard point is set by region. }\end{array}$ \\
\hline Typhoon alert & $\begin{array}{l}\text { When any of the following are expected due to the typhoon: } \\
\text { 1. Strong wind (or wind wave) expected to reach warning levels; } \\
\text { 2. Total precipitation is expected to be more than } 20 \mathrm{~mm} \text {; } \\
\text { 3. Storm surge is expected to reach warning levels. }\end{array}$ \\
\hline
\end{tabular}


Table 2. Classifications of typhoon intensity

\begin{tabular}{|c|c|c|c|c|c|}
\hline \multicolumn{2}{|r|}{ KMA } & \multicolumn{2}{|c|}{ JMA } & \multicolumn{2}{|c|}{ WMO } \\
\hline Category & $\begin{array}{l}\text { Maximum sustained wind speed } \\
(\mathrm{m} / \mathrm{sec})\end{array}$ & Category & $\begin{array}{l}\text { Maximum sustained wind speed } \\
\text { (m/sec) }\end{array}$ & Category & $\begin{array}{l}\text { Maximum sustained wind speed } \\
(\mathrm{m} / \mathrm{sec})\end{array}$ \\
\hline Week & $17.2-24$ & Tropical depression & - & Tropical depression & Less than 17.2 \\
\hline Moderate & $25-32$ & Typhoon & - & Tropical storm & $17.2-24$ \\
\hline Strong & $33-43$ & Strong typhoon & 32.7-43.7 (64-84 kt) & Severe tropical storm & $25-32$ \\
\hline \multirow[t]{2}{*}{ Very strong } & 44 and over & Very strong typhoon & $43.7-54.0$ (85-104 kt) & Typhoon & 33 and over \\
\hline & & Violent typhoon & 54.0 and over (> $105 \mathrm{kt})$ & & \\
\hline
\end{tabular}

KMA, Korea Meteorological Administration; JMA, Japan Meteorological Administration; WMO, World Meteorological Organization.

Table 3. Characteristics of the selected typhoons

\begin{tabular}{|c|c|c|c|c|}
\hline Year & $\begin{array}{l}\text { Name of } \\
\text { typhoon }\end{array}$ & $\begin{array}{c}\text { Classification } \\
\text { (in Korea) }\end{array}$ & $\begin{array}{l}\text { Classification } \\
\text { (formed- } \\
\text { dissipated) }\end{array}$ & Effect \\
\hline \multirow[t]{3}{*}{2010} & Kompasu & Strong & Strong & Direct \\
\hline & Dianmu & Moderate & Strong & Direct \\
\hline & Malou & Weak & Weak & Indirect \\
\hline \multirow[t]{3}{*}{2011} & Meari & Moderate & Strong & Indirect \\
\hline & Muifa & Strong & Very strong & Indirect \\
\hline & Talas & Weak & Strong & Indirect \\
\hline \multirow[t]{5}{*}{2012} & Khanun & Weak & & Direct \\
\hline & Damrey & Strong & Strong & Indirect \\
\hline & Tembin & Weak & Very strong & Direct \\
\hline & Bolaven & Very strong & Very strong & Indirect \\
\hline & Sanba & Very strong & Very strong & Direct \\
\hline
\end{tabular}

Classification by the Korea Meteorological Agency.

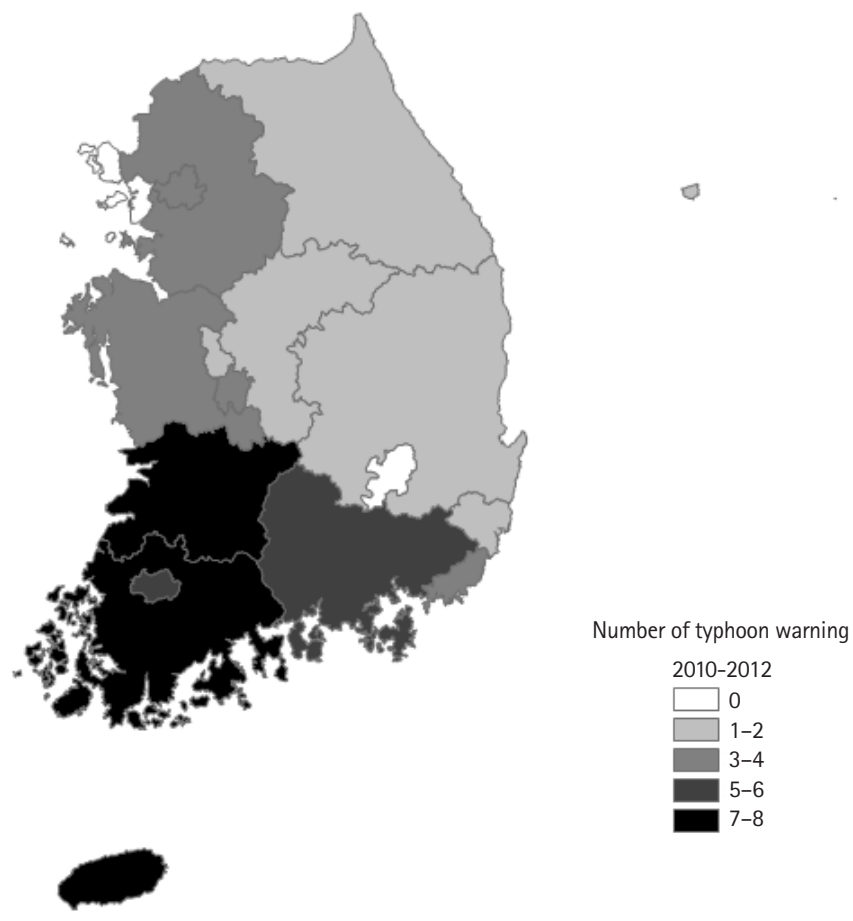

Fig. 1. The number of typhoon alerts. This figure shows the number of alerts activated by the Korea Meteorological Administration.

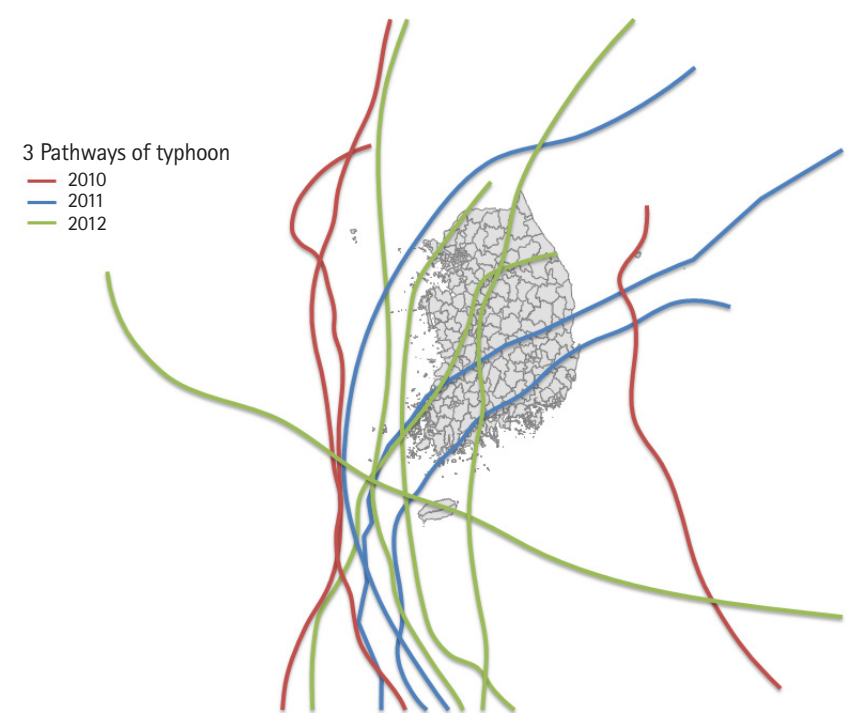

Fig. 2. Typhoons pathways. A total of 11 typhoons affected Korea during the study period. There were three typhoons in 2010, three in 2011, and five in 2012. Five made landfall and passed through the country; the others passed along the coast.

by EMS during the study period were selected for analysis. The patients were divided into two groups according to selection criteria. The response time was defined as the time interval from a patient's call for an ambulance to the arrival of the ambulance team at the patient's side. The total transport time was defined as the interval from the call to hospital arrival. Patient age, sex, and clinical characteristics were included in the analysis.

\section{Study outcomes}

The primary and secondary outcomes were EMS response time and total transportation time, respectively.

\section{Statistical analysis}

Pearson chi-square tests were used to compare baseline characteristics and t-tests were used to compare study variables related to EMS operational performance between the case and control 
groups. Analyses were performed using Stata ver. 13.0 (StataCorp., College Station, TX, USA). Typhoon impacts on land were extracted from digital maps using ArcGIS ver. 10 (Esri, Redlands, CA, USA).

\section{RESULTS}

A total of 11 typhoons affected Korea during the study period. There were three typhoons in 2010, three in 2011, and five in 2012 (Fig. 1). Five (45\%) typhoons made landfall and passed through, while the others passed near the coast. We used 'Kyungbo', which is the highest alert level in the Korea Meteorological Agency typhoon warning system.

We counted the number of alerts activated by the KMA by region (Fig. 2). Some areas had many alerts, including Jeollanamdo (eight), Jeju Island, and Jeollabukdo (seven). The southern part of Korea was disproportionately affected by typhoons.

Typhoons were categorized into the following four groups based on strength by the KMA (Table 2) ${ }^{9}$ : two were level 1 (> $44 \mathrm{~m} / \mathrm{sec}$ ), three were level $2(33-43 \mathrm{~m} / \mathrm{sec})$, two were level $3(25-32 \mathrm{~m} / \mathrm{sec})$, and four were level 4 (17.2-24 m/sec). Cases were selected from

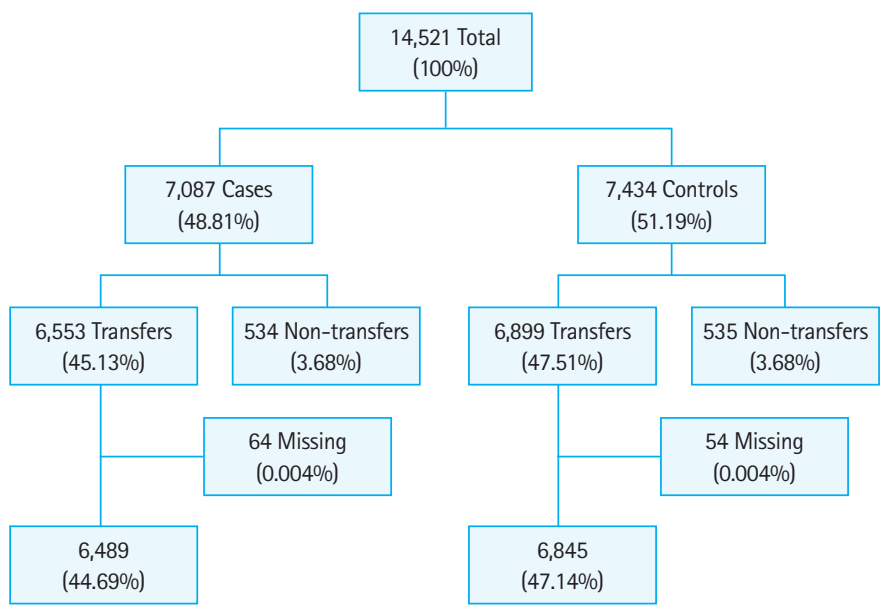

Fig. 3. Study flow diagram of patients. This figure shows the total number of emergency medical service responses and the selected numbers of cases and controls used in the analysis except for a non-transfer case and a missing case. among 16 days. The selected typhoons differed in characteristics (Table 3).

There were 14,521 EMS responses reported in the National Emergency Management Agency data. From these, 7,807 cases and 7,434 controls were selected for analysis. After excluding transfer and missing cases, a total of 6,489 cases and 6,845 controls were selected. There were no obvious differences between the baseline characteristics of the cases and controls (Fig. 3 and Table 4). However, there were statistically significant differences

Table 4. Baseline patient characteristics

\begin{tabular}{|c|c|c|c|c|}
\hline Variable & $\begin{array}{c}\text { Case } \\
(n=6,489)\end{array}$ & $\begin{array}{c}\text { Control } \\
(n=6,845)\end{array}$ & $\begin{array}{c}\text { Overall } \\
(n=13,334)\end{array}$ & P-value \\
\hline Sex & & & & 0.37 \\
\hline Male & $3,549(54.7)$ & 3,797 (55.5) & $7,346(55.1)$ & \\
\hline Female & $2,940(45.3)$ & $3,048(44.5)$ & $5,988(44.9)$ & \\
\hline Age (yr) & & & & 0.01 \\
\hline $0<$ age $\leq 15$ & $284(4.4)$ & $374(5.5)$ & $658(5.0)$ & \\
\hline $15<$ age $\leq 65$ & $3,976(61.3)$ & $4,153(60.7)$ & $8,129(61.0)$ & \\
\hline $65<$ age $\leq 100$ & $2,229(34.3)$ & 2,318 (33.9) & $4,547(34.1)$ & \\
\hline Trauma vs. disease & & & & 0.14 \\
\hline Disease & $3,371(51.9)$ & $3,644(53.2)$ & 7,015 (52.6) & \\
\hline Trauma & $3,118(48.0)$ & $3,201(46.8)$ & $6,319(47.4)$ & \\
\hline Requesting methods & & & & 0.98 \\
\hline Mobile phone & $1,326(20.4)$ & $1,405(20.5)$ & $2,731(20.5)$ & \\
\hline Land phone & 929 (14.3) & $984(14.4)$ & $1,913(14.3)$ & \\
\hline Other & $4,234(65.2)$ & $4,456(65.1)$ & $8,690(65.2)$ & \\
\hline Place of request & & & & $<0.001$ \\
\hline Residential area & $4,099(63.1)$ & $3,923(57.3)$ & $8,022(60.2)$ & \\
\hline Public place & 905 (13.9) & $968(14.1)$ & $1,873(14.1)$ & \\
\hline Outdoor & $821(12.6)$ & $1,225(17.9)$ & $2,046(15.3)$ & \\
\hline Other & $664(10.2)$ & $729(10.7)$ & $1,393(10.5)$ & \\
\hline Time of request & & & & 0.03 \\
\hline 00:00 $\leq$ time $<08: 00$ & 1,359 (20.9) & $1,330(19.4)$ & $2,689(20.2)$ & \\
\hline $08: 00 \leq$ time $<18: 00$ & $4,222(65.0)$ & $4,472(65.3)$ & $8,694(65.2)$ & \\
\hline $18: 00 \leq$ time $<24: 00$ & 908 (14.0) & $1,043(15.2)$ & $1,951(14.6)$ & \\
\hline Mental status & & & & 0.01 \\
\hline Alert & $5,830(89.7)$ & 6,099 (89.1) & $11,929(89.5)$ & \\
\hline Verbal response & $333(5.1)$ & 435 (6.4) & 768 (5.8) & \\
\hline Pain response & $186(2.9)$ & $186(2.7)$ & $372(2.8)$ & \\
\hline Unresponsive & $140(2.2)$ & 125 (1.8) & 265 (2.0) & \\
\hline
\end{tabular}

Table 5. Patient vital signs

\begin{tabular}{|c|c|c|c|c|c|c|c|c|c|c|}
\hline \multirow{2}{*}{ Variable } & \multicolumn{3}{|c|}{ Case } & \multicolumn{3}{|c|}{ Control } & \multicolumn{3}{|c|}{ Overall } & \multirow{2}{*}{ P-value } \\
\hline & Number & Mean & SD & Number & Mean & SD & Number & Mean & SD & \\
\hline SBP & 4,776 & 128.8 & 21.5 & 4,994 & 126.8 & 22.5 & 9,770 & 127.7 & 22.0 & $<0.001$ \\
\hline DBP & 4,776 & 81.1 & 14.2 & 4,994 & 79.4 & 16.9 & 9,770 & 80.2 & 15.7 & $<0.001$ \\
\hline Heart rate & 5,340 & 83.9 & 17.6 & 5,663 & 85.1 & 18.6 & 11,003 & 84.5 & 18.1 & 0.001 \\
\hline Respiratory rate & 5,101 & 18.2 & 3.6 & 5,268 & 18.3 & 3.7 & 10,369 & 18.2 & 3.7 & 0.58 \\
\hline Pulse oximetry & 5,257 & 97.0 & 4.1 & 5,592 & 97.1 & 4.0 & 10,849 & 97.0 & 4.0 & 0.88 \\
\hline
\end{tabular}

SD, standard deviation; SBP, systolic blood pressure; DBP, diastolic blood pressure. 
Table 6. Emergency medical service operational performance

\begin{tabular}{|c|c|c|c|c|c|c|c|c|c|c|}
\hline \multirow{2}{*}{ Variable } & \multicolumn{3}{|c|}{ Case } & \multicolumn{3}{|c|}{ Control } & \multicolumn{3}{|c|}{ Overall } & \multirow{2}{*}{ P-value } \\
\hline & Number & Mean & SD & Number & Mean & SD & Number & Mean & SD & \\
\hline Call to dispatch (min) & 6,484 & 1.3 & 2.2 & 6,838 & 1.3 & 2.4 & 13,322 & 1.3 & 2.3 & 0.80 \\
\hline Call to field (min) & 6,487 & 8.2 & 6.8 & 6,843 & 8.3 & 6.4 & 13,330 & 8.2 & 6.6 & 0.66 \\
\hline Call to hospital arrival (min) & 6,486 & 28.7 & 16.4 & 6,843 & 28.9 & 15.7 & 13,329 & 28.8 & 16.0 & 0.39 \\
\hline
\end{tabular}

SD, standard deviation.

in age, place, and time request. There were fewer patients aged 0 to 15 years in the case group and fewer patients were outdoors at the time of the EMS call in this group. There were fewer evening to midnight calls in the case group and more patients were unconscious (unresponsive, comatose) in this group. There were no significant differences in vital signs (blood pressure, heart rate, and oximetry) (Table 5).

EMS operational performance measured by the times from call to dispatch, call to the field, and call to the hospital did not differ significantly between cases and controls (Table 6). Call to hospital arrival times did not differ significantly between cases and controls (28.67, standard deviation 16.37 vs. 28.97, standard deviation 28.91; $P=0.39$ ).

\section{DISCUSSION}

Using nationwide typhoon and EMS data we found no statistically significant association between EMS response time and the incidence of typhoons. We also found there was no increased call volume during typhoons and the severity and clinical characteristics of patients also did not differ.

However, the case group was older than the control group. There were more patients with abnormal mental status in the case group, which may be due to a decrease in the mild to moderate group due to bad weather conditions. Despite these differences, there was no clinically consistent difference between the two groups that could be associated with typhoons.

The negative association between typhoons and call volume is contrary to previous studies, which reported decreased numbers of emergency department visits on the first day but an increased number after a typhoon, ${ }^{4,10-12}$ This may be due to the fact that the typhoons in Korea were not as strong as those in previous reports. ${ }^{4,13}$ Korea's well-established typhoon warning system along with its robust infrastructure and advanced irrigation system may have reduced the number of casualties during the typhoon events included in this study.

Our negative findings may be also due to the concrete road structure and drainage system. These systems prevent flooding of major roads, thus reducing ambulance travel time. Previous stud- ies have assessed hurricanes that caused severe flooding, which compromised EMS quality., ${ }^{414}$

Participation in outdoor activities is likely decreased during a typhoon. In the case group, $12.63 \%$ of EMS requests were to an outdoor location compared to $17 \%$ of controls $(P<0.001)$. Reduced traffic jams during a typhoon could also have counteracted EMS delays. However, we did not collect data specific to traffic flow.

This study has some potential limitations. First, the definition of typhoon exposure was defined in a meteorological manner, which could differ from that used in clinical or operational settings. We did not differentiate the specific characteristics of each typhoon such as precipitation and wind speed, which directly affect trauma incidence and ambulance operation. However, we did use the typhoon category alert, which incorporates many factors indicative of typhoon strength.

Second, the effect of weather is largely influenced by roads, housing, and urbanization, which were not considered in this study. In Korea, a large proportion of the population resides in high-rise apartments in very urbanized areas. Not adjusting for these factors could have contributed to the negative results.

Third, the travel distance between ambulance stations, patients, and destination hospitals was not considered. Ambulance crews could have headed to alternate hospitals that they would not have chosen under ordinary circumstances. However, alternate ambulance teams could also have been deployed due to typhoonassociated circumstances such as flooded roads. Therefore, there was no significant effect of typhoons on the EMS system during the study period.

\section{CONFLICT OF INTEREST}

No potential conflict of interest relevant to this article was reported.

\section{REFERENCES}

1. Emanuel K. Increasing destructiveness of tropical cyclones over the past 30 years. Nature 2005;436:686-8. 


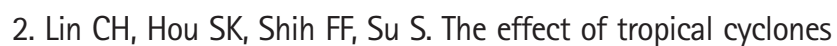
(typhoons) on emergency department visits. J Emerg Med 2013; 45:372-9.

3. Lee KE, Myung HN, Na W, Jang JY. Socio-demographic characteristics and leading causes of death among the casualties of meteorological events compared with all-cause deaths in Korea, 2000-2011. J Prev Med Public Health 2013;46:261-70.

4. Smith CM, Graffeo CS. Regional impact of Hurricane Isabel on emergency departments in coastal southeastern Virginia. Acad Emerg Med 2005;12:1201-5.

5. Pan CL, Chiu CW, Wen JC. Adaptation and promotion of emergency medical service transportation for climate change. Medicine (Baltimore) 2014;93:e186.

6. Choi DS, Kim T, Ro YS, et al. Extracorporeal life support and survival after out-of-hospital cardiac arrest in a nationwide registry: a propensity score-matched analysis. Resuscitation 2016;99:26-32.

7. Kim TH, Shin SD, Kim YJ, Kim CH, Kim JE. The scene time interval and basic life support termination of resuscitation rule in adult out-of-hospital cardiac arrest. J Korean Med Sci 2015; 30:104-9.
8. Arshi B, Mack WJ, Emanuel B. Invasive and noninvasive multimodal bedside monitoring in subarachnoid hemorrhage: a review of techniques and available data. Neurol Res Int 2013; 2013:987934.

9. Typhoon Committee. Typhoon Committee operational manual 2015. Macau: World Meteorological Organization; 2015.

10. Platz E, Cooper HP, Silvestri S, Siebert CF. The impact of a series of hurricanes on the visits to two central Florida Emergency Departments. J Emerg Med 2007;33:39-46.

11. Longmire AW, Ten Eyck RP. Morbidity of Hurricane Frederic. Ann Emerg Med 1984;13:334-8.

12. Kim H, Schwartz RM, Hirsch J, Silverman R, Liu B, Taioli E. Effect of Hurricane Sandy on Long Island Emergency Departments visits. Disaster Med Public Health Prep 2016;10:34450.

13. Brewer RD, Morris PD, Cole TB. Hurricane-related emergency department visits in an inland area: an analysis of the public health impact of Hurricane Hugo in North Carolina. Ann Emerg Med 1994;23:731-6.

14. Grech $V$, Scherb H. Hurricane Katrina: influence on the maleto-female birth ratio. Med Princ Pract 2015;24:477-85. 